\title{
Association of the CPT1A p.P479L Metabolic Gene Variant With Childhood Respiratory and Other Infectious Illness in Nunavut
}

\author{
Sorcha A. Collins ${ }^{1}$, Sharon Edmunds ${ }^{2}$, Gwen Healey Akearok ${ }^{3}$, J. Robert Thompson ${ }^{4}$, \\ Anders C. Erickson ${ }^{5}$, Elske Hildes-Ripstein ${ }^{6}$, Amber Miners $^{7}$, Martin Somerville ${ }^{8}$, \\ David M. Goldfarb ${ }^{9}$, Cheryl Rockman-Greenberg ${ }^{6}$ and Laura Arbour ${ }^{1 *}$ \\ ${ }^{1}$ Department of Medical Genetics, University of British Columbia, Vancouver, BC, Canada, ${ }^{2}$ Department of Research, \\ Monitoring, and Evaluation, Nunavut Tunngavik Inc., Iqaluit, NU, Canada, ${ }^{3}$ Qaujigiartiit Health Research Centre, Iqaluit, NU, \\ Canada, ${ }^{4}$ Cadham Provincial Laboratory, Winnipeg, MB, Canada, ${ }^{5}$ School of Population and Public Health, University of \\ British Columbia, Vancouver, BC, Canada, ${ }^{6}$ Department of Pediatrics and Child Health, University of Manitoba, Winnipeg, \\ MB, Canada, ${ }^{7}$ Department of Health, Government of Nunavut, lqaluit, NU, Canada, ${ }^{8}$ Department of Laboratory Medicine \\ and Pathobiology University of Toronto, Toronto, ON, Canada, ${ }^{9}$ Department of Pathology and Laboratory Medicine, \\ University of British Columbia, Vancouver, BC, Canada
}

OPEN ACCESS

Edited by:

Christoph Aebi,

University Children's Hospital

Bern, Switzerland

Reviewed by:

David Koeller,

OHSU Doernbecher Children's

Hospital, United States

Jean-Marc Nuoffer,

Bern University Hospital, Switzerland

*Correspondence:

Laura Arbour

larbour@uvic.ca

Specialty section: This article was submitted to Pediatric Infectious Diseases, a section of the journal

Frontiers in Pediatrics

Received: 09 March 2021 Accepted: 14 June 2021

Published: 06 July 2021

Citation:

Collins SA, Edmunds S, Akearok GH,

Thompson JR, Erickson AC,

Hildes-Ripstein E, Miners A,

Somerville M, Goldfarb DM, Rockman-Greenberg $C$ and Arbour $L$

(2021) Association of the CPT1A

p.P479L Metabolic Gene Variant With

Childhood Respiratory and Other

Infectious Illness in Nunavut.

Front. Pediatr. 9:678553.

doi: 10.3389/fped.2021.678553
Objective: Infectious illness, including lower respiratory tract infection (LRTI), is a leading cause of childhood morbidity and infant mortality in Inuit children in Nunavut Canada. The carnitine palmitoyltransferase 1A (CPT1A) p.P479L variant is common in arctic Indigenous populations of Alaska, Canada, and Greenland. CPT1A is a fatty acid oxidation enzyme expressed in the liver, immunocytes and other tissues, and is needed to use fats for energy during fasting. Previous association of the variant with early childhood infectious illness and infant death has been challenged because of sample size and limited adjustment for confounders. We evaluated whether the p.P479L variant is associated with infectious illness in Inuit children of Nunavut, Canada.

Methods: We conducted a retrospective clinical chart review of 2,225 Inuit children (0-5 years) for infectious illness (including otitis media, gastroenteritis, and hospital admission for LRTI), prenatal, perinatal, and socioeconomic indicators, subsequently linking to CPT1A genotype. Multivariable logistic regression adjusted for birth characteristics, breastfeeding, maternal smoking, food insecurity, and socioeconomic indicators.

Results: Overall, $27 \%$ of children were hospitalized for LRTI, $86 \%$ had otitis media and $50 \%$ had gastroenteritis. The p.P479L allele frequency was 0.82 . In multivariable analysis, p.P479L homozygosity was associated with LRTI admission (aOR:2.88 95\%Cl:1.46-5.64), otitis media (aOR:1.83, 95\%Cl:1.05-3.21), and gastroenteritis (aOR:1.74, 95\%Cl:1.09-2.77), compared to non-carriers.

Conclusion: Children homozygous for the p.P479L variant were more likely to experience infectious illness than non-carriers, including hospitalization for respiratory tract infections. Given the role of CPT1A in immunocytes, our findings indicate that more study is needed to determine if there is a role of the variant in immune response. Continued Inuit involvement is essential when considering next steps.

Keywords: Indigenous, Inuit, carnitine palmitoyltransferase 1A, infectious illness, p.P479L arctic variant, respiratory tract infection in children 


\section{INTRODUCTION}

Infants and children in Nunavut have high rates of infectious illness, in particular, infant hospitalizations for lower respiratory tract infections (LRTI; 234-306/1000) $(1,2)$ and otitis media ( $85 \%$ of children $<3$ years) (3). Nunavut also has an infant mortality rate four times the national average ( 21.5 vs. $4.5 / 1,000$ livebirths) (4), with sudden unexpected death and respiratory infection comprising the majority of post-neonatal deaths (5). Nunavut is Canada's northernmost territory and largest jurisdictional landmass, which is divided into three regions, Qikiqtani, Kivalliq, and Kitikmeot. The majority of Nunavut residents (referred to as Nunavummiut) identify as Inuit ( $80 \%$ of 40,000 inhabitants) $(6,7)$, with unique socio-cultural strengths and perspectives. Although social determinants of health and institutional structures that reinforce socioeconomic status influence health outcomes $(3,8,9)$, underlying genetic factors may also play a role. Studies have reported that the p.P479L variant of carnitine palmitoyltransferase $1 \mathrm{~A}$ (CPT1A) may contribute to the high rates of infectious illness and infant death in Northern Indigenous populations $(5,10-12)$.

Nunavut has a high prevalence of the p.P479L (c.1436C $>\mathrm{T}$, rs80356779) variant of CPT1A, which is prevalent in Indigenous populations of northern Canada, Alaska and Greenland (1318). The variant has been associated with a number of adverse infant and child health outcomes, including hypoglycemia (10, $19,20)$, seizures (21) and sudden unexpected infant death and infant death due to infection $(5,13,22)$. Preliminary studies have suggested the variant may be also be associated with infectious illness in early childhood $(11,12)$. CPT1A is the rate limiting enzyme of long chain fatty acid oxidation in a variety of tissues, including the liver, pancreas and immunocytes (23). Classic CPT1A deficiency (OMIM:255120) is a rare autosomal recessive disease presenting during infancy as hypoketotic hypoglycemia and metabolic decompensation triggered by prolonged fasting and/or vomiting, often precipitated by active infection (24). Unlike variants that cause classic CPT1A deficiency that abolish CPT1A activity, the CPT1A p.P479L variant, also known as the "arctic variant," is considered a mild variant with reported CPT1A activity of $2-22 \%$ of normal $(10,25)$.

Given the p.P479L variant's high frequency, there has been uncertainty regarding its clinical significance, which has created calls for larger and more comprehensive studies that include other risk factors important in these outcomes (26). We assessed early child health outcomes of 2,225 Inuit children residing in Nunavut to determine whether the CPT1A p.P479L variant is associated with infectious illness in the broader context of other relevant perinatal, postnatal and socioeconomic variables.

Abbreviations: CPT1A, carnitine palmitoyltransferase 1A; CWB, community well-being index; HWE, Hardy-Weinberg equilibrium; LRTI, lower respiratory tract infection; OM, otitis media; PTB, preterm birth; RSV, respiratory syncytial virus.

\section{METHODS}

\section{Ethics Statement}

The study was developed and conducted in partnership with Nunavut Tunngavik Inc. (NTI), the Qaujigiartiit Health Research Centre (QHRC) and the Government of Nunavut Department of Health. NTI is responsible for ensuring the implementation of and adherence to the Nunavut Land Claims Agreement and advocates for policies and programs that enhance Inuit wellbeing, including healthy children. The QHRC is a communityled research institute, fostering local leadership and engagement in research activities involving the health and well-being of Nunavummiut.

Study ethics approval was granted by the University of British Columbia, University of Victoria and University of Manitoba Research Ethics Boards, and a research license was granted by the Nunavut Research Institute.

\section{Data Sources}

We reviewed clinical charts of Inuit children born from 01Jan-2010 to 31-Dec-2013 at community health centers, Iqaluit Public Health and the Qikiqtani General Hospital in Iqaluit. All communities with more than 20 births/year (18/25 communities) were visited for chart review in all three Nunavut regions (Qikiqtaaluk, Kivalliq, and Kitikmeot). Information collected included birth data (gestational age, birth weight, place and type of birth, complications, newborn screening results), perinatal and postnatal exposures from prenatal, labor/delivery, newborn and well-baby records and medical information up to 5 years of age ( $0-5$ years). Medical data abstracted included reason for visit/admission, tests, treatments, outcomes, and medical diagnoses.

Inuit ethnicity was determined using mother's and/or infant's ancestry indicated on the chart. Food insecurity data were collected as recorded on the well-baby records for 2, 6, 12, 24, and 48-month visits using the primary caregiver answer to the question "since your baby was born/your last visit, were there times when the food for you and your family just did not last and there was no money to buy enough food?" Answers of "Often" or "Sometimes" were coded as Yes, "No/Never" as No, and "Don't know/refused" as missing. Breastfeeding data was collected from newborn records and well-baby records for 1 week -1 month, 2 , 6,12 , and 24 months visits.

Community SES was defined using the 2011 Statistics Canada Community Well-Being $(\mathrm{CWB})$ index that provides a measure of socioeconomic well-being for individual communities across Canada (27). The CWB is comprised of four components (education, labor force activity, income, and housing) combined into an index between 0 (lowest) and 100 (highest).

Outcome variables were admission for LRTI $(>24 \mathrm{~h}$ to regional/tertiary hospital), admission with respiratory syncytial virus (RSV; $>24 \mathrm{~h}$ to regional/tertiary hospital for laboratory confirmed RSV infection), otitis media, gastroenteritis (vomiting and/or diarrhea not otherwise explained) and dental interventions (restorations, extractions, treatment of infection, surgery). Repeat visits/admissions within 14 days were not counted. 


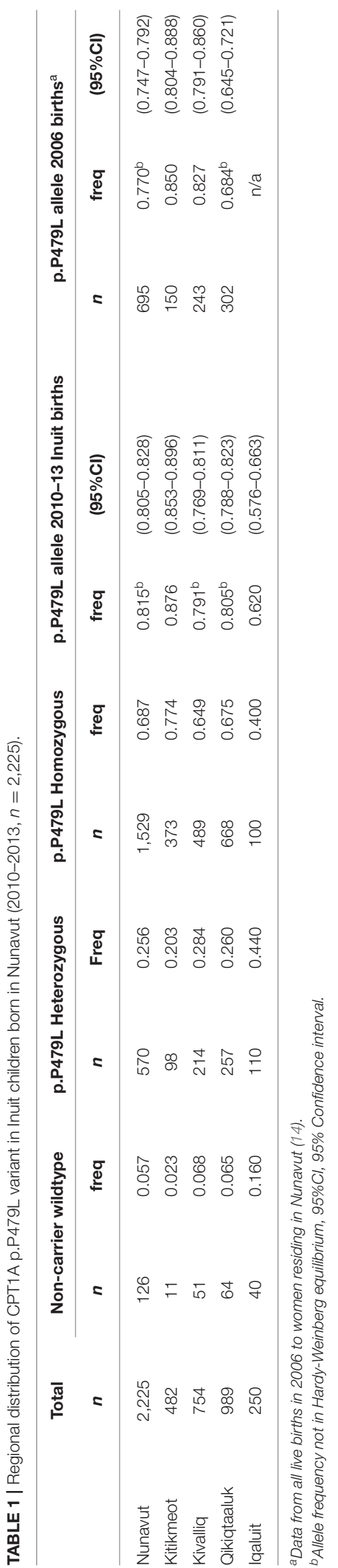

\section{CPT1A p.P479L Genotyping}

Retrospective CPT1A p.P479L (rs80356779) genotyping was conducted for all infants born to mothers residing in Nunavut between Jan 1, 2010 to Dec 31, 2013 by re-testing stored newborn dried blood spot cards. Testing was conducted by the newborn screening programme at Cadham Provincial Laboratory in Winnipeg Manitoba for all Kivalliq region births, as previously described (10), and by Newborn Screening Ontario at the Children's Hospital of Eastern Ontario for in Kitikmeot and Qikiqtaaluk births, as previously described (14). Genotype results were linked to the clinical information after the completion of the chart review. As a retrospective anonymized study, no CPT1A p.P479L results were returned to health care providers or families. A small portion of children in the study cohort had been tested for the p.P479L variant as part of a pilot newborn screening program. In the case of a positive result (p.P479L homozygous), the result was reported by letter to community health care providers advising that the clinical significance of the variant was uncertain but to avoid prolonged fasting. This information was collected from the clinical chart during the chart review.

\section{Statistical Analysis}

We used descriptive statistics to summarize differences in covariates and outcomes by CPT1A p.P479L variant status. We conducted univariable tests of statistical significance using logistic and linear regression to explore relationships between variables and outcomes and pairwise correlation tests to show the inter-relationships between the variables. We used complete case multivariable logistic regression to examine association of CPT1A p.P479L variant with outcomes using two models: Model 1 adjusted for $\mathrm{CWB}$ and residence in Iqaluit. Model 2 adjusted for CWB, residence in Iqaluit, sex, preterm birth (PTB; $<37$ weeks gestation), presence of major congenital anomalies (included in LRTI and RSV admission models only), postnatal maternal smoking, breastfeeding $\geq 6$ months and food insecurity. Odds ratios with $95 \%$ confidence intervals were considered statistically significant for two-tailed $p$-values $<0.05$.

We conducted sensitivity analysis using multiple imputation by chained equations to create missing values for preterm birth $(n=34)$, postnatal maternal smoking $(n=408)$, breastfeeding $\geq 6$ months $(n=145)$, and food insecurity $(n=455)$. All variables and outcomes were included in the imputation and 20 imputed data sets were created. Comparison of imputed data to complete case analysis was then performed. To investigate whether prior knowledge of p.P479L homozygosity impacted study results, we conducted a sensitivity analysis by running models 1 and 2 with (1) excluding cases with prior documented p.P479L homozygosity and (2) including a covariate for prior documented p.P479L homozygosity. Results were compared to complete case analysis.

Hardy-Weinberg equilibrium (HWE) was analyzed using the $\chi^{2}$ test with $p<0.05$ significance level for each region and the territorial capital Iqaluit, which has the largest population in Nunavut. Data were analyzed using Stata Statistical Software: Release 16SE (StataCorp LLC). 


\section{RESULTS}

Charts for 2,523 Inuit children were reviewed. Charts with only birth data were excluded from analysis $(n=60)$. CPT1A genotype linkage was successful for 2,225/2,463 records (90.3\%). Of those, $68.7 \%$ were p.P479L homozygous, $25.6 \%$ p.P479L heterozygous and $5.7 \%$ non-carrier wildtype (Table 1). The p.P479L allele was in HWE in Kitikmeot and the territorial capital (Iqaluit) but not Kivalliq, Qikiqtaaluk or for the population of Nunavut as a whole. Of the 2,225 children with p.P479L status information, 140 had p.P479L homozygous positive test results documented in the chart.

There were no significant differences in birth related characteristics between CPT1A genotype groups (Table 2). Pairwise correlation analyses showed p.P479L homozygosity was positively correlated with all health outcomes assessed, postnatal maternal smoking and food insecurity and was negatively correlated with $\mathrm{CWB}$ and residence in Iqaluit (Supplementary Table 1).

Overall, 607 (27.3\%) children were admitted to regional or tertiary hospital for LRTI, including 182 (8.2\%) admitted with RSV. The majority of children had one or more episodes of otitis media (86\%) and half of all children (50\%) had at least one episode of gastroenteritis (Table 3).

Results of univariable and multivariable logistic regression analysis are presented in Table 4. In univariable logistic regression analysis, p.P479L homozygosity was associated with all outcomes and p.P479L heterozygosity was associated with otitis media, dental interventions and gastroenteritis during infancy (Table 4). In multivariable regression analysis adjusting for CWB and residence in Iqaluit (Model 1), p.P479L homozygosity was associated with all outcomes except RSV admission in infancy and p.P479L heterozygosity was associated with otitis media and dental interventions in early childhood but not gastroenteritis during infancy.

Figure 1 shows the effect estimates for p.P479L homozygosity and heterozygosity after further adjustment for postnatal and socioeconomic variables (Model 2). p.P479L homozygosity was associated with LRTI admission (aOR:2.88 95\%CI:1.465.64), otitis media (aOR:1.83, 95\%CI:1.05-3.21), gastroenteritis (aOR:1.74, 95\%CI:1.09-2.77), and dental intervention (aOR:2.11, 95\%CI:1.22-3.66) in early childhood and p.P479L heterozygosity was associated with dental interventions (aOR:1.88, 95\%CI:1.073.32; Figure 1). In infancy ( $<1$ year of age), p.P479L homozygosity was associated with LRTI admission (aOR:2.79, 95\%CI:1.29-6.03), otitis media (aOR:1.87, 95\%CI:1.18-2.96), and gastroenteritis (aOR:2.32, 95\%CI:1.23-4.39) and p.P479L heterozygosity was associated with gastroenteritis (aOR:2.01, 95\%CI:1.04-3.87).

\section{Sensitivity Analysis}

To understand the impact of missing data in the study, we conducted multiple imputation and compared model results to complete case analysis. All statistically significant associations with p.P479L homozygosity were retained, and the effect estimates for p.P479L homozygosity with RSV admission and p.P479L heterozygosity with otitis media in early childhood no longer overlapped one (Table 4). However, the association of p.P479L heterozygosity with gastroenteritis in infancy was no longer statistically significant. We conducted a sensitivity analysis to investigate whether prior knowledge of p.P479L homozygosity impacted study results. All statistically significant associations between p.P479L homozygosity and outcomes were retained when records with documented p.P479L homozygosity were excluded from models $(n=140)$ or when models included adjustment for this information. Although there was slight increase or decrease of point estimates for the association of p.P479L homozygosity with some outcomes, there was no overall impact on the results of the study (see Supplementary Table 2).

\section{DISCUSSION}

The health status of Inuit children in Canada has garnered attention and concern for several decades $(1,28)$ and Inuit children living in Nunavut have some of the highest reported rates of infectious illness in Canada (1-3). Preliminary studies have implicated the CPT1A p.P479L variant as a possible risk factor for infectious illness in early childhood $(11,12)$; however, there has been some debate regarding the clinical significance of the variant and calls for larger, population-based comprehensive studies that adjust for known and suspected risk factors for adverse health outcomes (26).

In our comprehensive retrospective study of 2,225 Inuit children, the largest to date, we show that children homozygous for the p.P479L variant had significantly higher rates of infectious illness than non-carriers, which was independent of sex, preterm birth, residence in Iqaluit, breastfeeding for 6 months or longer, postnatal maternal smoking, food insecurity and CWB index (which includes measures of community-level housing, education, and income). Children homozygous for the variant were almost three times as likely to be admitted to hospital for LRTI. We noted that although p.P479L homozygosity was associated with early childhood RSV admission in Model 1 (CWB index and Iqaluit residence) confidence intervals in the full model overlapped one. Since RSV test results were not available for all LRTI admissions, this study may underrepresent the true prevalence of RSV admission, limiting the interpretation of this result.

Children homozygous for the p.P479L variant were also approximately twice as likely to have otitis media and gastroenteritis and require dental interventions than noncarriers in early childhood. Otitis media is associated with impaired hearing at 5 years of age and can have dramatic impacts on speech development and educational attainment (29-31). There are a number of risk factors associated with otitis media; including maternal smoking and preterm birth; however, the association of p.P479L variant with otitis media remained statistically significant after adjustment for many of those factors.

Our results corroborate and are consistent with studies in British Columbia and Alaska reporting association of the p.P479L variant with hospitalization and infectious illness. In 2013, Gessner et al. (11) reported that p.P479L homozygosity 
TABLE 2 | Infant and maternal characteristics by CPT1A p.P479L variant for Inuit children born in Nunavut (2010-2013, $n=2,225)$.

\begin{tabular}{|c|c|c|c|c|c|}
\hline & $\begin{array}{c}\text { Non-carrier } \\
\text { wildtype } \\
\text { (n=126) } \\
n \text { /total (\%) }\end{array}$ & $\begin{array}{c}\text { p.P479L } \\
\text { heterozygous } \\
(n=570) \\
n \text { /total }(\%)\end{array}$ & $\begin{array}{c}\text { p.P479L } \\
\text { homozygous } \\
\text { ( } n=1,529) \\
n \text { /total (\%) }\end{array}$ & $\begin{array}{l}\text { Total cohort } \\
(n=2,225) \\
n \text { /total }(\%)\end{array}$ & $n(\%)$ \\
\hline Male & $58 / 126(46.0)$ & 289/570 (50.7) & 773/1,529 (50.6) & 1,120/2,225 (50.3) & 0 \\
\hline Preterm (<37 weeks) & 13/124 (10.5) & 67/565 (12.0) & $186 / 1,502(12.4)$ & 266/2,191 (12.1) & $34(1.5)$ \\
\hline mean GA & 38.7 weeks & 38.5 weeks & 38.2 weeks & 38.1 weeks & \\
\hline Term LBW (<2,500 g) & 0/123 (0) & $6 / 560(1.1)$ & $33 / 1,513(2.2)$ & $39 / 2,196(1.8)$ & $29(1.3)$ \\
\hline mean birth weight & $3,526 \mathrm{~g}$ & $3,456 \mathrm{~g}$ & $3,344 \mathrm{~g}$ & $3,341 \mathrm{~g}$ & \\
\hline Mat. age $<20$ years & 26/117 (22.2) & 98/529 (18.5) & $331 / 1,421$ (23.3) & 455/2,067 (22.0) & $158(7.1)$ \\
\hline Mean mat. age & 24 years & 24 years & 24 years & 24 years & \\
\hline Breastfeeding $\geq 6$ months & 43/123 (35.0) & 200/531 (37.7) & 490/1,426 (34.4) & 733/2,080 (35.2) & $145(6.5)$ \\
\hline Postnatal mat smk. & $61 / 94(64.9)$ & $384 / 460$ (83.4) & 1,119/1,263 (88.6) & 1,564/1,817 (86.1) & 408 (18.3) \\
\hline Food insecurity $<5$ years & 21/93 (22.6) & $149 / 450$ (33.1) & $577 / 1,227$ (47.0) & $747 / 1,770(42.2)$ & $455(20.4)$ \\
\hline
\end{tabular}

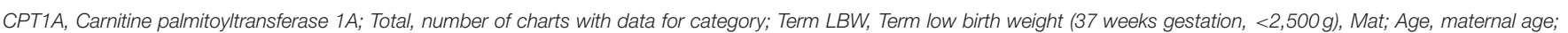
Postnatal mat smk., Postnatal maternal smoking; GA, Gestational age.

TABLE 3 | Infectious illness by CPT1A p.P479L variant in Inuit children born in Nunavut $(2010-2013, n=2,225)$.

\begin{tabular}{|c|c|c|c|c|c|c|}
\hline \multirow[b]{2}{*}{ Outcome variable } & \multirow{2}{*}{$\frac{\text { Cohort }(n=2,225)}{n(\%)}$} & \multirow{2}{*}{$\begin{array}{c}\text { Non-carrier }(n=126) \\
n(\%)\end{array}$} & \multicolumn{2}{|c|}{ p.P479L heterozygous $(n=570)$} & \multicolumn{2}{|c|}{ p.P479L homozygous $(n=1,529)$} \\
\hline & & & $n(\%)$ & cOR $(95 \% \mathrm{Cl})$ & $n(\%)$ & cOR $(95 \% \mathrm{Cl})$ \\
\hline LRTI admitted, 0-5 years & 607 (27.3) & $15(11.9)$ & $105(18.4)$ & $1.7(0.93-3.0)$ & $487(31.9)$ & $3.5(2.0-6.0)$ \\
\hline LRTI admitted, infants (<1 year) & $449(20.2)$ & $9(7.1)$ & $71(12.5)$ & $1.9(0.89-3.8)$ & $369(24.1)$ & $4.2(2.1-8.3)$ \\
\hline RSV admitted, 0-5 years & $182(8.2)$ & $3(2.4)$ & $39(6.8)$ & $3.0(0.92-9.9)$ & $140(9.2)$ & $4.1(1.3-13.2)$ \\
\hline RSV admitted, infants ( $<1$ year) & $149(6.7)$ & $3(2.4)$ & $31(5.4)$ & $2.4(0.71-7.9)$ & $115(7.5)$ & $3.3(1.0-10.7)$ \\
\hline Otitis media, $0-5$ years & 1,919 (86.3) & $90(71.4)$ & $474(83.2)$ & $2.0(1.3-3.1)$ & 1,355 (88.6) & $3.1(2.1-4.7)$ \\
\hline Otitis media $3+$ episodes, $0-5$ years & $1,290(57.2)$ & $48(37.8)$ & $274(46.8)$ & $1.4(0.98-2.1)$ & $954(62.4)$ & $2.8(1.9-4.1)$ \\
\hline Otitis media, infants (<1 year) & $1,413(63.5)$ & $54(42.9)$ & $320(56.1)$ & $1.7(1.2-2.5)$ & $1,039(67.9)$ & $2.8(2.0-4.1)$ \\
\hline Gastroenteritis, $0-5$ years & $1,109(49.8)$ & $47(37.3)$ & $249(43.7)$ & $1.3(0.87-1.9)$ & $813(53.1)$ & $1.9(1.3-2.8)$ \\
\hline Gastroenteritis, infants ( $<1$ year) & $637(28.6)$ & $19(15.1)$ & $137(24.0)$ & $1.8(1.1-3.0)$ & $481(31.5)$ & $2.6(1.6-4.3)$ \\
\hline Dental interventions, $0-5$ years & $794(35.7)$ & $22(17.5)$ & $188(33.0)$ & $2.3(1.4-3.8)$ & $584(38.2)$ & $2.9(1.8-4.7)$ \\
\hline Mean num. admits/illnesses & Mean $(95 \% \mathrm{Cl})$ & Mean $(95 \% \mathrm{Cl})$ & Mean (95\% Cl) & Coef. $(p)$ & Mean (95\% Cl) & Coef. (p) \\
\hline LRTI admits, $0-5$ years & $0.42(0.38-0.46)$ & $0.15(0.07-0.23)$ & $0.24(0.20-0.29)$ & $0.09(0.278)$ & $0.51(0.46-0.56)$ & $0.36(<0.001)$ \\
\hline mean age 1st admit (months) & $9.0(8.1-9.9)$ & $15.4(5.5-25.2)$ & $12.0(9.3-14.6)$ & $-3.4(0.280)$ & $8.6(7.7-9.6)$ & $-6.7(0.025)$ \\
\hline Otitis media, $0-5$ years & $4.1(3.9-4.3)$ & $2.4(1.9-2.8)$ & $3.0(2.8-3.3)$ & $0.62(0.11)$ & $4.6(4.4-4.9)$ & $2.3(<0.001)$ \\
\hline mean age at 1st episode (months) & $11.6(11.2-12.1)$ & $13.6(11.2-16.2)$ & $13.6(12.5-14.7)$ & $-0.02(0.988)$ & $10.8(10.3-11.3)$ & $-2.8(0.015)$ \\
\hline Gastroenteritis, 0-5 years & $0.93(0.88-0.99)$ & $0.61(0.43-0.79)$ & $0.73(0.64-0.81)$ & $0.12(0.35)$ & $1.0(0.97-1.1)$ & $0.43(<0.001)$ \\
\hline mean age at 1st episode (months) & $14.1(13.4-14.8)$ & $17.4(13.6-21.2)$ & $14.5(12.9-16.0)$ & $-2.9(0.123)$ & $13.8(13.0-14.6)$ & $-3.6(0.044)$ \\
\hline
\end{tabular}

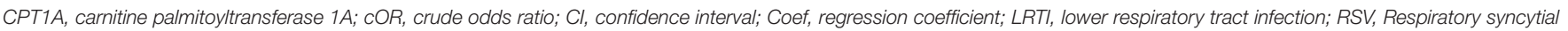
virus; Dental, major dental interventions (extractions, restorations, surgeries).

was associated with increased risk of otitis media (aOR:3.0, 95\%CI:1.8-5.1) and LRTI admission (aOR:2.5, 95\%CI:1.6-4.0) and admission for any reason in 427 Alaska Native children (0-2.5 years), adjusting for maternal education, age, prenatal smoking and alcohol use, prenatal care and birth weight. In 2019, Sinclair et al. (12) found that p.P479L homozygosity was associated with admissions for LRTI (OR:6.0, 95\%CI:1.622.4), otitis media (OR:13.5, 95\%CI:1.5-109.4) and dental caries (OR:3.4, 95\%CI:1.5-7.8) in 150 children (<7 years) in a British
Columbia First Nations community. In our current analysis, we demonstrate that adjustment for SES indicators, including food security and community level measures of education and housing, reduced but did not abolish the association with LRTI admission, otitis media and dental interventions.

Children homozygous for the CPT1A p.P479L variant may experience a more severe illness due to impaired ketogenesis or impaired response of the immune system during infection. As an enzyme critical for long chain fatty acid oxidation, CPT1A 
TABLE 4 | Multivariable logistic regression results for association of CPT1A p.P479L variant with infectious illness during infancy and early childhood in Inuit children residing in Nunavut (2010-2013).

\begin{tabular}{|c|c|c|c|c|c|c|c|c|}
\hline & \multicolumn{4}{|c|}{ Early childhood (0-5 years) } & \multicolumn{4}{|c|}{ Infants ( $<1$ year) } \\
\hline & \multicolumn{2}{|c|}{ p.P479L homozygous } & \multicolumn{2}{|c|}{ p.P479L heterozygous } & \multicolumn{2}{|c|}{ p.P479L homozygous } & \multicolumn{2}{|c|}{ p.P479L heterozygous } \\
\hline & OR $(95 \% \mathrm{Cl})$ & $p$ & OR $(95 \% \mathrm{Cl})$ & $P$ & OR $(95 \% \mathrm{Cl})$ & $\boldsymbol{P}$ & OR $(95 \% \mathrm{Cl})$ & $p$ \\
\hline \multicolumn{9}{|l|}{ LRTI admission } \\
\hline Univariable & $3.47(2.00-6.01)$ & $<0.001$ & $1.66(0.93-2.95)$ & 0.082 & $4.15(2.08-8.25)$ & $<0.001$ & $1.82(0.89-3.76)$ & 0.103 \\
\hline Model $1^{a}$ & $3.19(1.82-5.60)$ & $<0.001$ & $1.62(0.90-2.90)$ & 0.101 & $3.28(1.63-6.58)$ & 0.001 & $1.64(0.79-3.39)$ & 0.182 \\
\hline Model $2(c c)^{b}$ & $2.88(1.46-5.64)$ & 0.002 & $1.63(0.81-3.29)$ & 0.169 & $2.79(1.29-6.03)$ & 0.009 & $1.54(0.69-3.44)$ & 0.291 \\
\hline Model 2 (imputed) ${ }^{\mathrm{b}}$ & $3.11(1.75-5.52)$ & $<0.001$ & $1.64(0.91-2.98)$ & 0.102 & $3.26(1.60-6.64)$ & 0.001 & $1.69(0.81-3.54)$ & 0.161 \\
\hline \multicolumn{9}{|l|}{ RSV admission } \\
\hline Univariable & $4.13(1.30-13.15)$ & 0.016 & 3.02 (0.92-9.92) & 0.069 & $3.33(1.04-10.64)$ & 0.042 & $2.36(0.71-7.85)$ & 0.161 \\
\hline Model $1^{a}$ & $4.17(1.29-13.47)$ & 0.017 & $3.07(0.93-10.13)$ & 0.066 & 2.89 (0.89-9.36) & 0.077 & $2.23(0.67-7.43)$ & 0.193 \\
\hline Model $2(\mathrm{cc})^{\mathrm{b}}$ & $3.04(0.92-10.07)$ & 0.068 & $2.61(0.77-8.82)$ & 0.122 & $2.02(0.61-6.71)$ & 0.249 & $1.79(0.52-6.11)$ & 0.355 \\
\hline Model 2 (imputed) ${ }^{b}$ & $4.12(1.27-13.41)$ & 0.019 & $3.11(0.94-10.32)$ & 0.064 & $2.81(0.86-9.18)$ & 0.087 & $2.23(0.66-7.47)$ & 0.194 \\
\hline \multicolumn{9}{|l|}{ Otitis media } \\
\hline Univariable & $3.12(2.05-4.73)$ & $<0.001$ & $1.97(1.26-3.07)$ & 0.003 & $2.83(1.96-4.09)$ & $<0.001$ & $1.70(1.15-2.51)$ & 0.008 \\
\hline Model $1^{a}$ & $1.95(1.25-3.06)$ & 0.004 & $1.64(1.03-2.61)$ & 0.036 & $1.83(1.23-2.70)$ & 0.003 & $1.41(0.94-2.12)$ & 0.096 \\
\hline Model $2(\mathrm{cc})^{\mathrm{c}}$ & $1.83(1.05-3.21)$ & 0.034 & $1.67(0.94-2.99)$ & 0.081 & $1.87(1.18-2.96)$ & 0.008 & $1.53(0.95-2.47)$ & 0.084 \\
\hline Model 2 (imputed) ${ }^{c}$ & $1.96(1.24-3.10)$ & 0.004 & $1.64(1.02-2.62)$ & 0.040 & $1.90(1.28-2.82)$ & 0.002 & $1.44(0.95-2.17)$ & 0.082 \\
\hline \multicolumn{9}{|l|}{ Gastroenteritis } \\
\hline Univariable & $1.91(1.31-2.78)$ & 0.001 & $1.30(0.87-1.93)$ & 0.197 & $2.58(1.57-4.26)$ & $<0.001$ & 1.79 (1.06-3.02) & 0.030 \\
\hline Model $1^{a}$ & $1.62(1.10-2.38)$ & 0.015 & $1.21(0.81-1.81)$ & 0.344 & $2.00(1.20-3.34)$ & 0.008 & $1.61(0.95-2.73)$ & 0.078 \\
\hline Model $2(\mathrm{cc})^{\mathrm{c}}$ & $1.74(1.09-2.77)$ & 0.020 & $1.32(0.81-2.13)$ & 0.264 & $2.32(1.23-4.39)$ & 0.010 & $2.01(1.04-3.87)$ & 0.037 \\
\hline Model 2 (imputed) ${ }^{\mathrm{c}}$ & $1.65(1.11-2.44)$ & 0.013 & $1.24(0.83-1.86)$ & 0.302 & 2.00 (1.19-3.36) & 0.009 & $1.62(0.95-2.77)$ & 0.075 \\
\hline \multicolumn{9}{|c|}{ Dental interventions } \\
\hline Univariable & $3.14(1.98-5.00)$ & $<0.001$ & $2.37(1.46-3.84)$ & $<0.001$ & & & & \\
\hline Model $1^{\mathrm{a}}$ & $2.23(1.38-3.58)$ & 0.001 & 2.06 (1.26-3.36) & 0.004 & & & & \\
\hline Model $2(\mathrm{cc})^{\mathrm{c}}$ & $2.11(1.22-3.66)$ & 0.008 & $1.88(1.07-3.32)$ & 0.029 & & & & \\
\hline Model 2 (imputed)c & $2.27(1.41-3.67)$ & 0.001 & $2.09(1.27-3.41)$ & 0.003 & & & & \\
\hline
\end{tabular}

${ }^{a}$ Adjusted for community socioeconomic status (CWB) and residence in lqaluit.

${ }^{b}$ Adjusted for community socioeconomic status (CWB) and residence in lqaluit, sex, preterm birth (<37 weeks gestation), major congenital anomalies, postnatal maternal smoking, breastfeeding $\geq 6$ months, and food insecurity.

${ }^{C}$ Adjusted for community socioeconomic status (CWB) and residence in lqaluit, sex, preterm birth, postnatal maternal smoking, breastfeeding $\geq 6$ months and food insecurity.

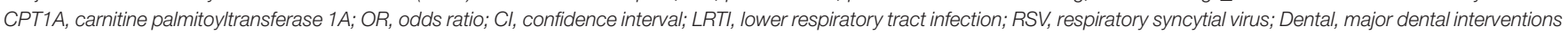
(extractions, restorations, surgeries); cc, complete case analysis, $n=1,697$.

Bold values indicate two-tailed $p<0.05$.

is important in a number of tissues, including liver energy homeostasis during fasting, pancreatic glucagon secretion and $\mathrm{T}$ cell development and survival (32-34). CD8+ memory $\mathrm{T}$ cells (32), especially resident memory $\mathrm{T}$ cells (33), and CD4+ Th17 and Treg (34) cells have high demands for fatty acid oxidation and CPT1A activity. Currently, there is no evidence regarding whether the p.P479L variant impairs immune response and/or memory $\mathrm{T}$ cell response to repeat infection in humans; however, a recent study of a multiple sclerosis (MS) mouse model (autoimmune encephalomyelitis) found that the CPT1A p.P479L variant may affect the function of cells important in immunity (35). The authors reported that knock-in mice expressing the Cpt1a p.P479L gene variant were resistant to the induction of autoimmune encephalomyelitis, suggesting that the variant conferred protection through blocking the activation of lipid metabolism and/or through impairing the activation of immune system (35). In the context of our study, these results suggest that there should be further studies on the potential effect of altered CPT1A function on immunity to determine if there is evidence of T-cell impact and subsequent impact on vaccine effectiveness for those with the CPT1A p.P479L variant.

The high prevalence of the p.P479L variant in Inuit populations, where the variant flourished to become the major allele $(14,36)$, suggests an historical advantage compared to non-carriers (18) likely due to synergy with traditional diet practices $(10,15)$. This speculation is supported by reports of strong signals of positive selection at the site of the nucleotide change (rs80356779) (16-18) and the association of the variant with protection from adverse lipid profiles in adults, including higher HDL-cholesterol and ApoA1 and lower adiposity $(15,36)$. There is also evidence of an interaction between traditional food intake and the p.P479L variant, supporting the possibility 


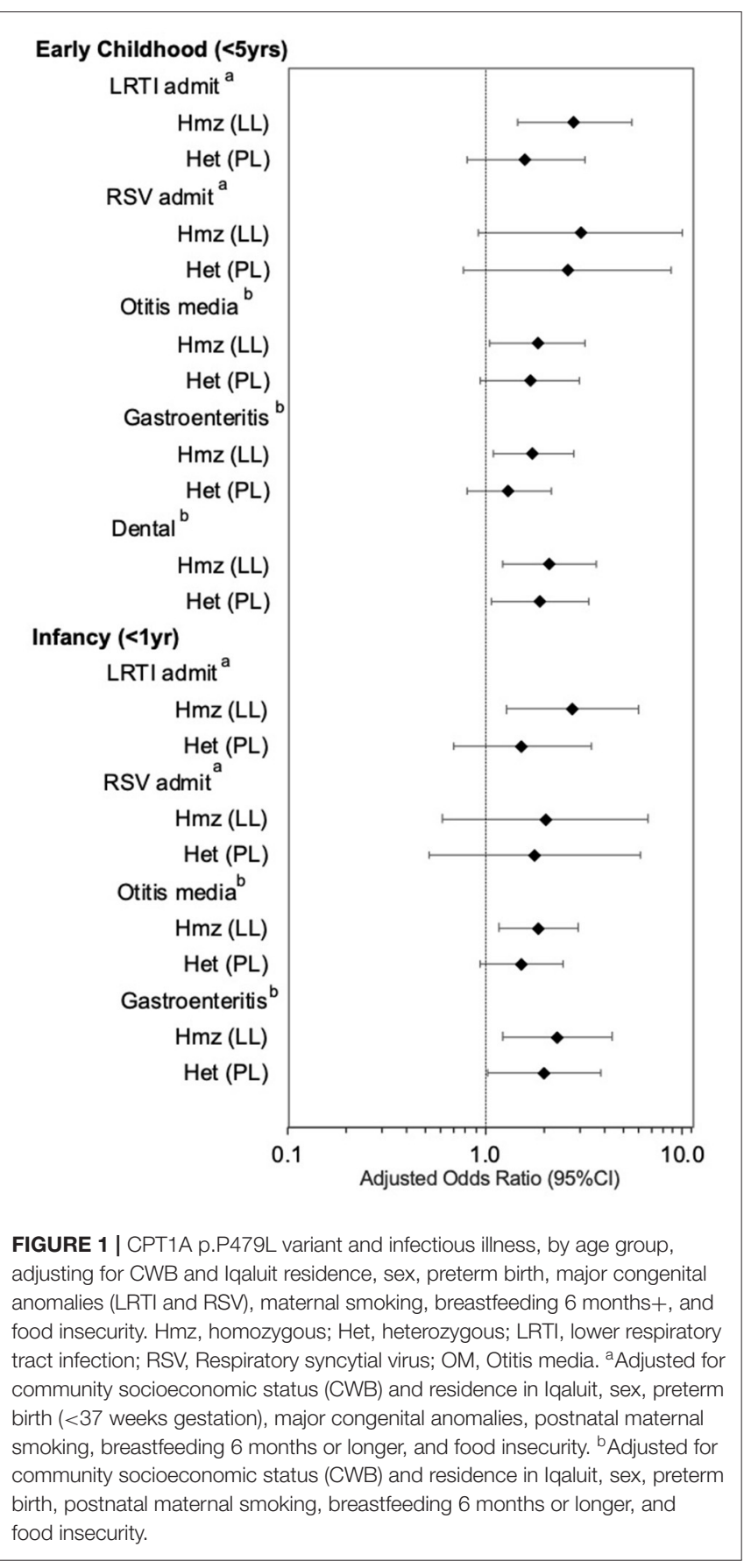

that this interaction may have influenced selection (37). The p.P479L variant is moderately insensitive to malonyl-CoA with fed state residual activity four times control (0.094 vs. 0.023 $\mathrm{nmol} / \mathrm{min} / \mathrm{mg}$ ) (25), suggesting a degree of fatty acid metabolism occurs even when carbohydrate is present. Within the harsh arctic environment, this may have conferred advantage for those utilizing a traditional "hunter's diet" rich in omega-3 marinebased fats with little carbohydrate $(10,15)$.

In our study, p.P479L heterozygosity was associated with dental interventions, gastroenteritis in infancy and with otitis media in Model 1 (adjusting for CWB index and Iqaluit residence), indicating a possible heterozygous effect and could indicate an additive effect for the variant (Tables 3, 4). These results are thought-provoking since classic CPT1A deficiency is considered an autosomal recessive disorder. Other studies have reported intermediate results for p.P479L heterozygotes. In their study of adult Greenlanders, Skotte et al. (16) reported an association between the p.P479L variant and height with an average reduction in height of $2.1 \mathrm{~cm}$ per copy of the variant $\left(p=1.04 \times 10^{-9}\right)$, which suggests an additive effect. Furthermore, although the associations were not statistically significant, Sinclair et al. (12) found p.P479L heterozygotes had an intermediate effect (between wildtype and homozygotes) for LRTI admission and dental caries. Rajakumar et al. (36) also found an intermediary heterozygote effect on HDL-cholesterol and associated apoA-I levels. Taken together, these results support a possible additive effect in these outcomes.

Tobacco smoke exposure, household overcrowding and food insecurity are associated with childhood infectious illness $(38,39)$. In the current cohort, $86 \%$ of women reported smoking postnatally and $17.5 \%$ of children lived in homes with three or more people/bedroom. In pairwise correlation tests, p.P479L homozygosity was significantly correlated with maternal postnatal smoking, food insecurity and CWB, suggesting that some risk associated with the p.P479L variant may be due to these underlying factors; however, p.P479L homozygosity remained significantly associated with LRTI admission, otitis media, gastroenteritis and dental interventions after adjustment for these variables. Breastfeeding is associated with reduced risk for adverse early child health outcomes, including infant mortality and infectious illness $(2,40)$. Health Canada recommends breastfeeding for at least 6 months since longer duration of breastfeeding is protective against infectious illness in infancy (41); however, adjustment for breastfeeding 6 months or longer did not impact the association of p.P479L homozygosity with infectious illness outcomes.

The results of this study need to be interpreted in the context of the population where the study was conducted, which, as demonstrated in this study, has significant challenges with housing, food security and access to secondary and tertiary medical care due to the remote nature of Nunavut communities. Of consideration, genetic research in Indigenous communities may inadvertently cause harm by creating stigma for those with a described "risk" allele (9). However, there is also harm in avoiding research that may provide insights into health disparity. Health related research, and in particular, genetic research, is best carried out in partnership with Indigenous people to ensure that the balance of harms and benefits are fully considered throughout the process (42). It is important to note that this research was carried out with the support and on-going partnership of the Inuit organization that is responsible for the land and the people of Nunavut (NTI), and the grass roots Inuit research organization that leads relevant health research within the territory (QHRC). Next steps to address the impact of the p.P479L variant need to be developed in partnership with Inuit leadership and engagement with communities. 


\section{LIMITATIONS}

This was a retrospective chart review study. In the study cohort, 9\% of records did not have CPT1A genotype information and were excluded from analysis. The CPT1A p.P479L variant was the only genetic variant studied; we cannot rule out that other genetic variants may have contributed to the results. The p.P479L variant departed from HWE in two Nunavut regions, which may be due to positive selection for the variant (16-18) since selection can cause deviations of HWE, or may be due to other unknown contributors or underlying differences in population structure. To mitigate the latter risk, the analysis was limited to Inuit children (as recorded on chart after self-identification); however, we were not able to assess non-Inuit admixture within the self-identified Inuit population.

\section{CONCLUSION}

Children homozygous for the p.P479L variant were more likely to be admitted for lower respiratory tract infections and were more likely to have otitis media, gastroenteritis and dental interventions, supporting a role of the variant in infant and child health and well-being. Our results have international implications given the known prevalence of the p.P479L variant in circumpolar populations and should be further addressed with the goal of reducing infant and child morbidity and mortality. Further studies to determine if the CPT1A p.P479L variant impacts immune response to infection are needed, information that will be important for the development of culturally relevant public health strategies in reducing childhood morbidity and mortality.

\section{DATA AVAILABILITY STATEMENT}

The data analyzed in this study is subject to the following licenses/restrictions: UBC-UVic-Government of Nunavut Research Disclosure Agreement M17-00229. Requests to access these datasets should be directed to Dr. Laura Arbour, larbour@uvic.ca.

\section{AUTHOR CONTRIBUTIONS}

SC: participated in all aspects of the study including study conception and design, acquisition, analysis and interpretation of data, drafting of the initial manuscript, and revision of the manuscript. CR-G: participated in the study conception and design, acquisition, and interpretation of data along with revision of the manuscript. JRT: participated in design and acquisition of study data along with revision of the manuscript. SE, AE, EH-R, DG, AM, and MS: participated in the study design and interpretation of the data along with revision of the manuscript. LA: participated in the study conception and design, analysis, interpretation of data, and revision of the manuscript. All authors approved the final manuscript as submitted and agree to be accountable for all aspects of the work.

\section{FUNDING}

Funding was provided by the Canadian Institutes of Health Research Partnership for Health Systems Improvement Grant (LA; FRN 122187) and the Government of Nunavut (RSA 1718-214).

\section{ACKNOWLEDGMENTS}

We greatly appreciate the dedicated efforts of Dr. Geraldine Osborne and Dr. Kim Barker in the initiation and implementation of this project. We also are grateful for the invaluable contributions of the chart reviewers, Lily Amagoalik, Bronwyn Barker, Simona Bene Watts, Erika Bloomfield, Sarah Douglas, Lawrence Gillman, Sidney Horlick, Karen Jacob, Nahid Mahmood, Paria Rad, Malcolm Tan, and Maria van Noordenne. We would also like to acknowledge the important contributions of the laboratory personnel at the newborn screening programs at Cadham Provincial Laboratory (Winnipeg) and CHEO (Ottawa). We appreciate the review and helpful comments of earlier versions of this manuscript by Dr. Andre Corriveau (former Chief Medical Health Officer of Northwest Territories) and Dr. Jasmine Pawa (Deputy Chief Medical Officer of Health of Nunavut).

\section{SUPPLEMENTARY MATERIAL}

The Supplementary Material for this article can be found online at: https://www.frontiersin.org/articles/10.3389/fped. 2021.678553/full\#supplementary-material

\section{REFERENCES}

1. Banerji A, Panzov V, Young M, Robinson J, Lee B, Moraes T, et al. Hospital admissions for lower respiratory tract infections among infants in the Canadian Arctic: a cohort study. CMAJ Open. (2016) 4:E615-22. doi: 10.9778/cmajo.20150051

2. Banerji A, Greenberg D, White LF, Macdonald WA, Saxton A, Thomas E, et al. Risk factors and viruses associated with hospitalization due to lower respiratory tract infections in Canadian Inuit children: a case-control study. Pediatr Infect Dis J. (2009) 28:697-701. doi: 10.1097/INF.0b013e31819f1f89

3. Egeland GM, Faraj N, Osborne G. Cultural, socioeconomic, and health indicators among Inuit preschoolers: Nunavut Inuit Child Health Survey, 2007-2008. Rural Remote Health. (2010) 10:1365. doi: 10.22605/RRH1365
4. Statistics Canada. Table 13-10-0713-01 Infant Deaths and Mortality Rates, by Age Group. Ottawa, ON (2017).

5. Collins SA, Surmala P, Osborne G, Greenberg C, Bathory LW, EdmundsPotvin S, et al. Causes and risk factors for infant mortality in Nunavut, Canada 1999-2011. BMC Pediatr. (2012) 12:190. doi: 10.1186/1471-2431-12-190

6. Statistics Canada. Table 17-10-0005-01 Population Estimates on July 1st, by Age and Sex. Ottawa, ON (2019).

7. Statistics Canada. Aboriginal Peoples in Canada in 2006: Inuit, Métis and First Nations, 2006 census: findings. Catalogue no. 97-558-XIE. Ottawa, ON (2008).

8. Patterson M, Flinn S, Barker K. Addressing tuberculosis among Inuit in Canada. Can Commun Dis Rep. (2018) 44:82-5. doi: 10.14745/ccdr.v44i34a02

9. Claw KG, Anderson MZ, Begay RL, Tsosie KS, Fox K, Garrison NA. A framework for enhancing ethical genomic research with Indigenous 
communities. Nat Commun. (2018) 9:2957. doi: 10.1038/s41467-01805188-3

10. Greenberg CR, Dilling LA, Thompson GR, Seargeant LE, Haworth JC, Phillips S, et al. The paradox of the carnitine palmitoyltransferase type Ia P479L variant in Canadian Aboriginal populations. Mol Genet Metab. (2009) 96:2017. doi: $10.1016 /$ j.ymgme.2008.12.018

11. Gessner BD, Gillingham MB, Wood T, Koeller DM. Association of a genetic variant of carnitine palmitoyltransferase $1 \mathrm{~A}$ with infections in Alaska Native children. J Pediatr. (2013) 163:1716-21. doi: 10.1016/j.jpeds.2013.07.010

12. Sinclair G, Collins S, Arbour L, Vallance H. The p.P479L variant in CPT1A is associated with infectious disease in a BC First Nation. Paediatr Child Health. (2019) 24:e111-5. doi: 10.1093/pch/pxy106

13. Sinclair G, Collins S, Popescu O, McFadden D, Arbour L, Vallance HD. Carnitine palmitoyltransferase I and sudden unexpected infant death in British Columbia First Nations. Pediatrics. (2012) 130:e1162-9. doi: 10.1542/peds.2011-2924

14. Collins SA, Sinclair G, McIntosh S, Bamforth F, Thompson GR, Sobol I, et al. Carnitine palmitoyltransferase 1A (CPT1A) P479L prevalence in live newborns in Yukon, Northwest Territories, and Nunavut. Mol Genet Metab. (2010) 101:200-4. doi: 10.1016/j.ymgme.2010.07.013

15. Lemas DJ, Wiener HW, O’Brien DM, Hopkins S, Stanhope KL, Havel PJ, et al. Genetic polymorphisms in carnitine palmitoyltransferase $1 \mathrm{~A}$ gene are associated with variation in body composition and fasting lipid traits in Yup'ik Eskimos. J Lipid Res. (2012) 53:175-84. doi: 10.1194/jlr.P018952

16. Skotte L, Koch A, Yakimov V, Zhou S, Søborg B, Andersson M, et al. CPT1A missense mutation associated with fatty acid metabolism and reduced height in Greenlanders. Circ Cardiovasc Genet. (2017) 10:e001618. doi: 10.1161/CIRCGENETICS.116.001618

17. Zhou S, Xiong L, Xie P, Ambalavanan A, Bourassa CV, Dionne-Laporte $A$, et al. Increased missense mutation burden of fatty acid metabolism related genes in Nunavik Inuit population. PLoS ONE. (2015) 10:e0128255. doi: 10.1371/journal.pone.0128255

18. Clemente FJ, Cardona A, Inchley CE, Peter BM, Jacobs G, Pagani L, et al. A selective sweep on a deleterious mutation in CPT1A in arctic populations. Am J Hum Genet. (2014) 95:584-9. doi: 10.1016/j.ajhg.2014.09.016

19. Gillingham MB, Hirschfeld M, Lowe S, Matern D, Shoemaker J, Lambert WE, et al. Impaired fasting tolerance among Alaska native children with a common carnitine palmitoyltransferase 1A sequence variant. Mol Genet Metab. (2011) 104:261-4. doi: 10.1016/j.ymgme.2011.06.017

20. Collins SA, Hildes-Ripstein GE, Thompson JR, Edmunds S, Miners A, Rockman-Greenberg C, et al. Neonatal hypoglycemia and the CPT1A P479L variant in term newborns: a retrospective cohort study of Inuit newborns from Kivalliq Nunavut. Paediatr Child Health. (2020) 2020:pxaa039. doi: $10.1093 / \mathrm{pch} / \mathrm{pxaa} 039$

21. Greenberg CR, Stannard KM, Webb JA. CPT1 P479L variant: clinical significance amongst Inuit children in Canada [abstract]. In: 4th International Meeting on Indigenous Child Health. Secure Our Future: Advancing Circles of Caring. Vancouver, BC. (2011).

22. Gessner BD, Wood T, Johnson MA, Richards CS, Koeller DM. Evidence for an association between infant mortality and homozygosity for the arctic variant of carnitine palmitoyltransferase 1A. Genet Med Off J Am Coll Med Genet. (2016) 18:933-9. doi: 10.1038/gim.2015.197

23. McGarry JD. The mitochondrial carnitine palmitoyltransferase system: its broadening role in fuel homoeostasis and new insights into its molecular features. Biochem Soc Trans. (1995) 23:321-4. doi: 10.1042/bst0230321

24. Bonnefont J-P, Demaugre F, Prip-Buus C, Saudubray JM, Brivet M, Abadi $\mathrm{N}$, et al. Carnitine palmitoyltransferase deficiencies. Mol Genet Metab. (1999) 68:424-40. doi: 10.1006/mgme.1999.2938

25. Brown NF, Mullur RS, Subramanian I, Esser V, Bennett MJ, Saudubray J$\mathrm{M}$, et al. Molecular characterization of L-CPT I deficiency in six patients: insights into function of the native enzyme. J Lipid Res. (2001) 42:1134-42. doi: 10.1016/S0022-2275(20)31604-7

26. Fohner AE, Garrison NA, Austin MA, Burke W. Carnitine palmitoyltransferase 1A P479L and infant death: policy implications of emerging data. Genet Med. (2017) 19:851. doi: 10.1038/gim.2016.202

27. Indigenous and Northern Affairs Canada. Community Well-Being Index. Report on Trends in Inuit Communities, 1981 to 2016. Ottawa, ON: Government of Canada (2019). Available online at: https://www.sac-isc.gc.ca/ eng/1421175988866/1557322849888 (accessed August 8, 2020).
28. Sheppard AJ, Hetherington R. A decade of research in Inuit children, youth, and maternal health in Canada: areas of concentrations and scarcities. Int J Circumpolar Health. (2012) 71:18383. doi: 10.3402/ijch.v71i0. 18383

29. Macintyre EA, Karr CJ, Koehoorn M, Demers P, Tamburic L, Lencar $\mathrm{C}$, et al. Otitis media incidence and risk factors in a population-based birth cohort. Paediatr Child Health. (2010) 15:437-42. doi: 10.1093/pch/ 15.7.437

30. Bowd AD. Otitis media: health and social consequences for aboriginal youth in Canada's north. Int J Circumpolar Health. (2005) 64:5-15. doi: $10.3402 /$ ijch.v64i1.17949

31. Wals PD, Lemeur JB, Ayukawa H, Proulx JF. Middle ear abnormalities at age 5 years in relation with early onset otitis media and number of episodes, in the Inuit population of Nunavik, Quebec, Canada. Int J Circumpolar Health. (2019) 78:1599269. doi: 10.1080/22423982.2019.1599269

32. van der Windt GJW, Everts B, Chang C-H, Curtis JD, Freitas TC Amiel E, et al. Mitochondrial respiratory capacity is a critical regulator of CD8+ T cell memory development. Immunity. (2012) 36:68-78. doi: 10.1016/j.immuni.2011.12.007

33. Pan Y, Tian T, Park CO, Lofftus SY, Mei S, Liu X, et al. Survival of tissueresident memory $\mathrm{T}$ cells requires exogenous lipid uptake and metabolism. Nature. (2017) 543:252-6. doi: 10.1038/nature21379

34. Lochner M, Berod L, Sparwasser T. Fatty acid metabolism in the regulation of $\mathrm{T}$ cell function. Trends Immunol. (2015) 36:81-91. doi: 10.1016/j.it.2014.12.005

35. Mørkholt AS, Trabjerg MS, Oklinski MKE, Bolther L, Kroese LJ, Pritchard CEJ, et al. CPT1A plays a key role in the development and treatment of multiple sclerosis and experimental autoimmune encephalomyelitis. Sci Rep. (2019) 9:13299. doi: 10.1038/s41598-019-49868-6

36. Rajakumar C, Ban MR, Cao H, Young TK, Bjerregaard P, Hegele RA Carnitine palmitoyltransferase IA polymorphism P479L is common in Greenland Inuit and is associated with elevated plasma apolipoprotein A-I. J Lipid Res. (2009) 50:1223-8. doi: 10.1194/jlr.P900001-JLR200

37. Senftleber N, Jørgensen ME, Jørsboe E, Imamura F, Forouhi NG, Larsen CL, et al. Genetic study of the Arctic CPT1A variant suggests that its effect on fatty acid levels is modulated by traditional Inuit diet. Eur J Hum Genet. (2020) 28:1592-601. doi: 10.1038/s41431-020-0674-0

38. Mehaffey K, Higginson A, Cowan J, Osborne GM, Arbour LT. Materna smoking at first prenatal visit as a marker of risk for adverse pregnancy outcomes in the Qikiqtaaluk (Baffin) Region. Rural Remote Health. (2010) 10:1484. doi: 10.22605/RRH1484

39. Ruiz-Castell M, Muckle G, Dewailly É, Jacobson JL, Jacobson SW, Ayotte P, et al. Household crowding and food Insecurity among Inuit families with schoolaged children in the Canadian Arctic. Am J Public Health. (2015) 105:e122-32. doi: 10.2105/AJPH.2014.302290

40. Badets N, Hudon T, Wendt M, Statistics Canada. Association between breastfeeding and select chronic conditions among off-reserve First Nations, Métis and Inuit children in Canada. Health Rep. (2017) 1-14.

41. Health Canada, Canadian Paediatric Society, Dietitians of Canada, Breastfeeding Committee for Canada. Nutrition for healthy term infants: recommendations from birth to six months. Can J Diet Pract Res Publ Dietit Can Rev Can Prat Rech En Diet Une Publ Diet Can. (2012) 73:204. doi: 10.3148/73.4.2012.204

42. Arbour L, Cook D. DNA on loan: issues to consider when carrying out genetic research with aboriginal families and communities. Community Genet. (2006) 9:153-60. doi: 10.1159/000092651

Conflict of Interest: The authors declare that the research was conducted in the absence of any commercial or financial relationships that could be construed as a potential conflict of interest.

Copyright $\odot 2021$ Collins, Edmunds, Akearok, Thompson, Erickson, Hildes-Ripstein, Miners, Somerville, Goldfarb, Rockman-Greenberg and Arbour. This is an openaccess article distributed under the terms of the Creative Commons Attribution License (CC BY). The use, distribution or reproduction in other forums is permitted, provided the original author(s) and the copyright owner(s) are credited and that the original publication in this journal is cited, in accordance with accepted academic practice. No use, distribution or reproduction is permitted which does not comply with these terms. 